\title{
WILLINGNESS TO JOIN AND PAY FOR THE NEWLY PROPOSED SOCIAL HEALTH INSURANCE AMONG TEACHERS IN WOLAITA SODO TOWN, SOUTH ETHIOPIA
}

\author{
Tesfamichael Alaro Agago ${ }^{1}$, Mirkuzie Woldie ${ }^{1}$, Shimeles Ololo ${ }^{1}$
}

\section{ABSTRACT}

BACKGROUND: Cost-sharing between beneficiaries and governments is critical to achieve universal health care coverage. To address this, Ethiopia is currently introducing Social Health Insurance. However, there has been limited evidence on willingness to join the newly proposed insurance scheme in the country. The purpose of this study is to assess willingness to join and pay for the scheme among teachers in Wolaita Sodo Town government educational institutions, South Ethiopia.

METHODS: A cross-sectional study was conducted from February 5 to March 10, 2012 on 335 teachers. Stratified simple random sampling technique was used and data were collected using structured interviewer administered questionnaire. Binary and multiple logistic regressions were used to estimate the crude and adjusted odds ratios for willingness to pay.

RESULTS: Three hundred twenty-eight teachers participated in the study with response rate of 98\%. About 55\% of the teachers had never heard of any type of health insurance scheme. However, $74.4 \%$ of them were willing to pay for the suggested insurance scheme. About $47 \%$ of those who were willing to pay agreed to contribute greater than or equal to $4 \%$ of their monthly salaries. Willingness to pay was more likely among those who had heard about health insurance, had previous history of inability to pay for medical bills and achieved higher educational status.

CONCLUSION: The majority of the teachers were willing to join social health insurance; however, adequate awareness creation and discussion should be made with all employees at various levels for the successful implementation of the scheme.

KEYWORDS: Social health insurance, South Ethiopia, willingness to join, willingness to pay

DOI: http://dx.doi.org/10.4314/ejhs.v24i3.2

\section{INTRODUCTION}

Affordability of health care is a key issue in most countries. In middle-and low-income countries, ensuring affordable health care is high on the development agenda given the large number of people lacking sufficient financial means to access health services (1).

In many developing countries, lack of adequate health care budget is a severe problem. Innovative ways to raise funds for the provision of health services such as developing risk-sharing mechanisms are often sought (2).
Moreover, looking for ways of properly and effectively financing health care is one of the most important preoccupations of governments everywhere. Although this problem affects both developed and poor countries, it is more acute in developing countries since they cannot collect a high proportion of their gross domestic product in taxes (3).

Social health insurance (SHI) is a financing scheme where money is pooled into a common fund and used for paying for healthcare costs of members (4). SHI pools low- and high-risk people's failure to address risks, and allows

${ }^{1}$ Department of Health Services Management, Jimma University, Ethiopia

Corresponding Author: Shimeles Ololo, Email: shimelessos@yahoo.com 
enrollees to contribute based on their ability to pay (5). Furthermore, SHI establishment has been advocated by the World Health Organization as a key to achieving universal coverage of health care and to ensure access to health services, particularly for the disadvantaged in less developed countries (6).

Thus, developed countries often use SHI to mobilize funds and pool risks. However, low and middle-income countries rarely use this approach and rely mostly on general revenues and direct out-of-pocket payments as sources of health care financing (5). Nevertheless, escalating health care costs, inadequate tax revenues and unsustainable donor funding have alerted governments of developing countries towards the fact that their health sectors need money from sources other than conventional financing sources (7).

Similarly, health financing has been a major challenge for Ethiopia. In Ethiopia, the coverage with formal health insurance is very minimal, representing only $0.02 \%$ to $0.03 \%$ of the total population between 1997 and 1998 (8). Similarly as of 2008, only $1.1 \%$ of Ethiopians had any kind of insurance and the government spends $1 \%$ of its health expenditure on insurance activities (9).

In order to address this problem and create equitable financing mechanism, the government of Ethiopia is currently undertaking a number of activities to introduce SHI with the overall objective of achieving universal access (10). Studies conducted in different parts of Africa and Asia reported that different socio-demographic and economic factors were responsible for low level of willingness to pay (WTP) for SHI (18-20). However, to the best of the authors' knowledge there was limited empirical evidence on willingness to join and pay for newly proposed SHI scheme in Ethiopia has been available.

Hence, before SHI Proclamation No.690/2010 comes in to force and is implemented, the study would give insight to policy makers and implementers how to support stakeholder participation and enable informed choice at the individual level. The study would also provide the parameters to underpin financial models needed to evaluate expansion plans and set equitable and sustainable tariffs. Furthermore, the study would also be a springboard for other investigators who might be interested to conduct further studies in this area.

\section{METHODS AND MATERIALS}

The study was conducted in Sodo Town, Wolaita Zone. Sodo is a town in south-central Ethiopia, which is the administrative center of Wolaita Zone of the Southern Nations, Nationalities and Peoples Region (SNNPR). Sodo town lies at about $330 \mathrm{~km}$ south of Addis Ababa, along the main highway to Arbaminch via Hossana, and $157 \mathrm{~km}$ away from Hawassa City. The town has 12 governmental and 9 non-governmental educational institutions with 1460 and 586 teachers respectively.

This cross-sectional study was conducted from February 5 to March 10, 2012. The source population was all teachers in government educational institutions in Sodo Town. Samples of teachers currently working in government educational institutions of Sodo Town having served for at least three months, and Ethiopians by nationality were studied. The sample size was determined by using single population proportion formula with the following assumptions: proportion of teachers willing to pay for $\mathrm{SHI}=$ $50 \%(\mathrm{p}=0.5), 95 \%$ confidence interval $(\mathrm{Z}=1.96)$, and margin of error $(\mathrm{d}=0.05)$. The sample size was 384; by using finite population correction formula and adding $10 \%$ for potential non-response, the final sample size became 335 .

A stratified simple random sampling technique was employed to select study participants. A total of 12 government teaching institutions found in the town were stratified based on primary level, secondary level and higher educational institutions. The total sample was proportionally allocated to each of the stratum based on the number of teachers in each stratum. The sampling frame for each stratum was made by merging the list of teachers, and samples were selected from each stratum using simple random sampling technique.

The questionnaire was prepared in English, translated into Amharic and back translated into English to check for consistency and was pretested on $5 \%$ of the total sample size in Gesebu Town. Discussion was also conducted with teachers on government educational institutions in Gesebu Town for settling starting point of the bidding game.

The Data were collected using structured questionnaire adapted from different studies (11- 
15) and modified to fit the local context. The questionnaire sought information on socio demographics, individual characteristics of the respondents, and the willingness to join and pay for SHI. Ten data collectors, who were diploma holders in health science, and two supervisors, who were first degree holders in health science, were recruited and received training.

Face-to-face interview was conducted before which the interviewers described the intentions of SHI scheme proposed by the government to the study participants. Iddirs (indigenous funeral insurance) were selected to be used as a reference point to explain SHI and to help respondents to visualize the new scenario (SHI) in the context of their personal experience and knowledge. The description included the SHI benefits as well as the payment vehicle for premium contributions. The benefits as well as payment vehicle were in line with Proclamation No. 690/2010, a proclamation to provide for SHI.

Respondents were asked about their maximum WTP for SHI when they first expressed their willingness to join. Subsequently, respondents were invited to choose a lottery ticket from a stack of unmarked envelope. Each respondent was randomly assigned to one of two initial values; $4 \%$ of monthly salary and $5 \%$ of monthly salary. A maximum of three trials were performed with each respondent if the respondent was not satisfied with the results of the earlier

Table 1: Selected socio-demographic characteristics of teachers in government educational institutions of Wolaita Sodo Town, South Ethiopia, February-March 2012 (N=328)

\begin{tabular}{|c|c|c|c|c|c|}
\hline Characteristics & Responses & $\begin{array}{l}\text { Primary } \\
\text { level }\end{array}$ & $\begin{array}{l}\text { Secondary } \\
\text { level }\end{array}$ & $\begin{array}{l}\text { Higher Education } \\
\text { institution }\end{array}$ & Total \\
\hline & & No $(\%)$ & No $(\%)$ & No $(\%)$ & No $(\%)$ \\
\hline \multirow[t]{2}{*}{ Sex } & Male & $79(53.7 \%)$ & $52(75.4 \%)$ & $103(92.0 \%)$ & $234(71.3 \%)$ \\
\hline & Female & $68(46.3 \%)$ & $17(24.6 \%)$ & 9 & $94(28.7 \%)$ \\
\hline \multirow{3}{*}{$\begin{array}{l}\text { Educational } \\
\text { status }\end{array}$} & Diploma & $119(81.0 \%)$ & 6 & 3 & $128(39.0 \%)$ \\
\hline & Bachelor & $19(12.9 \%)$ & $63(91.3 \%)$ & $58(51.8 \%)$ & $140(42.7 \%)$ \\
\hline & Others $\dagger$ & 9 & 0 & $51(45.5 \%)$ & $60(18.3 \%)$ \\
\hline \multirow{3}{*}{ Marital status } & Never married & $13(8.8 \%)$ & $21(30.4 \%)$ & $84(75.0 \%)$ & $118(36.0 \%)$ \\
\hline & Currently married & $130(88.4 \%)$ & $47(68.1 \%)$ & $28(25.0 \%)$ & $205(62.5 \%)$ \\
\hline & Otherst & 4 & 1 & 0 & 5 \\
\hline \multirow[t]{4}{*}{ Ethnicity } & Wolaita & $90(61.2 \%)$ & $54(78.3 \%)$ & $34(30.4 \%)$ & $178(54.3 \%)$ \\
\hline & Amhara & $42(28.6 \%)$ & 6 & $34(30.4 \%)$ & $82(25.0 \%)$ \\
\hline & Oromo & $11(7.5 \%)$ & 2 & $16(14.3 \%)$ & $29(8.8 \%)$ \\
\hline & Others* & 6 & 5 & $28(25.0 \%)$ & $39(11.9 \%)$ \\
\hline
\end{tabular}

\footnotetext{
${ }^{\mathrm{I}}$ NB: *Gurage, Dawro, Tigre, Gamo; $†$ Masters, PhD, TTI certificate; $\ddagger$ Divorced, widows
} increased the bid by $1 \%$ until the respondent says 'no' and vice versa (16).

Data were double-entered by using EpiData version 3.1, and analyzed using SPSS for Windows version 16.0. Frequency distribution of dependent and independent variables were worked out. Bivariate analysis was carried out to determine associations of selected variables with dependent variables and p-value of less than or equal to 0.25 was taken as a cut-off point to candidate variables for the final multiple logistic regression models. Independent predictors were determined using adjusted odds ratio with 95\% confidence interval in multiple regression analysis.

Prior to data collection, ethical clearance was obtained from Ethical Clearance Committee of the College of Public Health \& Medical Sciences of Jimma University. Respondents were requested for their verbal consent to participate in the study. Moreover, confidentiality was assured for the information provided by using coding system and did not use any personal identifiers.

\section{RESULTS}

Socio-demographic characteristics of respondents Three hundred twenty-eight teachers from government educational institutions participated in the study with response rate of $98 \%$. 
Of them, $147(44.8 \%), 69(21.1 \%)$, and 112 $(34.1 \%)$ were from primary level, secondary level, and higher educational institutions respectively. Two hundred thirty-four (71.3\%) of the teachers in government educational institutions were males. Concerning educational status, $42.7 \%$ had bachelor degrees. The median age was 33 (SD $\pm 10.29)$ years. Two hundred and five $(62.5 \%)$ were married, followed by unmarried with 118 $(36 \%)$ (Table1).

Health status and heath care utilization: Out of the total of 328 teachers, $129(39.3 \%)$ had at least one episode of illness over the past two months preceding the survey. Out of those who had episodes of illness, $69.2 \%$ responded that the illness episodes were not serious, whereas 31 (23.9\%), and 6 teacher responded that their illnesses were very serious and quite serious respectively. Of those who experienced at least one episode of illness over the past two months before the survey, $113(87.6 \%)$ used out of pocket money, $12(9 \%)$ used borrowed money, and the remaining used government fee as a source of payment for medical expenses.

Level of awareness about health insurance scheme: More than half $(55.2 \%)$ of the teachers in this study have never heard of the health insurance scheme. More specifically, 100 (68.0\%) were from primary level, $49(71.0 \%)$ from secondary level, and $32(28.6 \%)$ from higher educational institutions. The two most commonly stated reasons for not willing to join the proposed social health insurance scheme were fear of poor implementation and that the scheme might not cover all needed services for $65(69.1 \%)$ and 25 $(26.6 \%)$ of teachers respectively (Table 2).

Table 2: Ever heard of the health insurance scheme and the Reason for unwillingness to join the proposed social health insurance scheme among teachers in government educational institutions of Wolaita Sodo town, South Ethiopia, February-March 2012.

\begin{tabular}{|c|c|c|c|c|c|}
\hline \multirow[t]{2}{*}{ Characteristics } & \multirow[t]{2}{*}{ Responses } & $\begin{array}{c}\begin{array}{c}\text { Primary } \\
\text { level }\end{array} \\
\end{array}$ & $\begin{array}{c}\text { Secondary } \\
\text { level }\end{array}$ & $\begin{array}{c}\text { Higher } \\
\text { institutions }\end{array}$ & \multirow[t]{2}{*}{ Total } \\
\hline & & No. $(\%)$ & No. $(\%)$ & No. $(\%)$ & \\
\hline \multirow{2}{*}{$\begin{array}{l}\text { Ever heard of } \\
\text { health insurance } \\
\text { scheme }\end{array}$} & Yes & $47(32.0)$ & $20(28.9)$ & $80(71.4)$ & $147(44.8)$ \\
\hline & No & $100(68.0)$ & $49(71.0)$ & $32(28.6)$ & $181(55.2)$ \\
\hline \multirow{5}{*}{$\begin{array}{l}\text { Reasons for not } \\
\text { willing to join the } \\
\text { scheme }\end{array}$} & $\begin{array}{l}\text { Always in good } \\
\text { health }\end{array}$ & 3 & 0 & 0 & 3 \\
\hline & $\begin{array}{l}\text { The scheme doesn't } \\
\text { cover all the needed } \\
\text { services }\end{array}$ & 5 & 8 & $12(29.3)$ & $25(26.6)$ \\
\hline & Poor implementation & $20(66.7)$ & $15(65.2)$ & $29(70.7)$ & $64(68.1)$ \\
\hline & Don't know & 2 & 0 & 0 & 2 \\
\hline & Total & $30(100)$ & $23(100)$ & $41(100)$ & $94(100)$ \\
\hline
\end{tabular}

Willingness to join and pay for social health insurance: Two hundred-thirty four $(71.3 \%)$ of the teachers were willing to join the proposed social health insurance scheme. More specifically, $41.5 \%$ were from higher educational institution, $37.6 \%$ from primary level, and $20.9 \%$ from secondary level. Out of the 234 teachers who were willing to join the proposed social health insurance scheme, $174(74.4 \%)$ were willing to pay for the scheme. Among them, 51.2\% were from higher educational institution, $26.4 \%$ from primary level, and $22.4 \%$ from secondary level (Table 3). 
Table 3: Willingness to join and pay for social health insurance among teachers in government educational institution of Wolaita Sodo town, South Ethiopia, February-March 2012

\begin{tabular}{lccccc}
\hline Characteristics & Response & $\begin{array}{c}\text { Primary } \\
\text { level }\end{array}$ & $\begin{array}{c}\text { Secondary } \\
\text { level }\end{array}$ & $\begin{array}{c}\text { Higher educational } \\
\text { institution }\end{array}$ & Total \\
\hline & & No $(\%)$ & No $(\%)$ & No $(\%)$ & No (\%) \\
\hline Willingness to & Yes & $88(37.6)$ & $49(20.9)$ & $97(41.5)$ & $234(71.3)$ \\
Join & No & $44(46.8)$ & $26(27.6)$ & $24(25.6)$ & $94(28.7)$ \\
Willingness to & Yes & $46(26.4)$ & $39(22.4)$ & $89(51.2)$ & $174(74.4)$ \\
Pay & No & $36(60)$ & $19(31.7)$ & $5(8.3)$ & $60(25.6)$ \\
\hline
\end{tabular}

Out of 174 teachers who were willing to pay more than half $(47.1 \%)$ of them were willing to contribute greater than or equal to $4 \%$ of their monthly salary as a premium (Figure 1). About one fourth of the respondents stated that they would not be willing to pay anything although they would be willing to join the social health insurance scheme. Out of 60 teachers who were not willing to pay, 35(58.3\%), 17 (28.3\%), and 8 $(13.3 \%)$ stated that it was the government's responsibility to finance the program, out of pocket payment is better, and contribution being non-refundable respectively as reasons for not willing to pay.

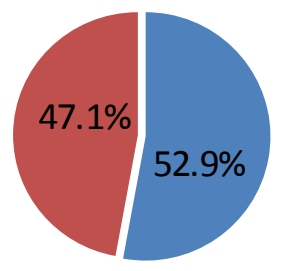

less than or equals to $3 \%$

greater than or equals to $4 \%$

Figure 1: Willingness to pay for social health insurance in percentage of monthly salary of the teachers in government educational institutions of Wolaita Sodo town, South Ethiopia, February-March 2012 (N=174)

Predictors of willingness to pay for SHI: Different socio-demographic and health insurance related variables were entered in stepwise regression after control for potential confounders like sex, marital status, age and the like was made. Respondents who had first degree were 3 times more likely to be willing to pay as compared to those teachers who were diploma holders (AOR = 2.982, $95 \%$ CI. 1.398, 6.361).

Those teachers who were unmarried were 2.7 times more likely to be willing to pay for the SHI scheme as compared to married counterparts.
It was also found that respondents who experienced problem of paying for medical bill over the past 12 months preceding the survey were 2.5 times more likely to be willing to pay for the SHI scheme as compared to those who didn't $(\mathrm{AOR}=2.574,95 \%$ CI. 1.152, 5.751). Moreover, individuals who heard about health insurance scheme were 2.5 times more likely to be willing to pay as compared to those teachers who have never heard $(\mathrm{AOR}=2.539,95 \%$ CI. 1.210, 5.326) (Table 
Table 4: Predictors of WTP for the proposed SHI scheme among teachers in government educational institution of Wolaita Sodo town, South Ethiopia, February-March 2012 (N=234)

\begin{tabular}{|c|c|c|c|c|}
\hline \multirow[t]{2}{*}{ Variables } & \multicolumn{2}{|c|}{ WTP SHI } & \multirow[t]{2}{*}{ COR $(95 \%$ CI $)$} & \multirow[t]{2}{*}{ AOR (95\% CI) } \\
\hline & Yes & No & & \\
\hline \multicolumn{5}{|l|}{ Marital status } \\
\hline Never married(ref) & 86 & 10 & 1 & 1 \\
\hline Married & 86 & 49 & $0.241(0.125,0.465) *$ & $0.370(0.169,0.808) \dagger$ \\
\hline \multicolumn{5}{|l|}{ Educational status } \\
\hline Diploma (ref) & 41 & 35 & 1 & 1 \\
\hline Bachelor degree & 87 & 20 & $3.757(1.958,7.208)^{*}$ & $2.982(1.398,6.361) \dagger$ \\
\hline Masters & 42 & 2 & $18.568(4.215,87.791)^{*}$ & $10.527(2.128,52.063) \dagger$ \\
\hline \multicolumn{5}{|c|}{ Heard about health insurance } \\
\hline No (ref) & 58 & 37 & 1 & 1 \\
\hline Yes & 116 & 23 & $3.217(1.751,5.912)^{*}$ & $2.539(1.210,5.326) \dagger$ \\
\hline \multicolumn{5}{|c|}{ Problem of paying medical bills } \\
\hline No (ref) & 110 & 46 & 1 & 1 \\
\hline yes & 64 & 14 & $1.673(0.848,3.299)^{*}$ & $2.574(1.152,5.755) \dagger$ \\
\hline \multicolumn{5}{|c|}{$\begin{array}{l}\text { Perception about who should pay } \\
\text { insurance premium }\end{array}$} \\
\hline Shared $b / n$ three (ref) & 90 & 20 & 1 & 1 \\
\hline Individuals & 21 & 3 & $1.566(0.229,1.355)$ & $1.950(0.480,7.915)$ \\
\hline Employers & 20 & 10 & $0.444(0.181,1.094)^{*}$ & $0.411(0.139,1.221)$ \\
\hline Government & 22 & 25 & $0.196(0.092,0.414) *$ & $0.290(0.121,0.695) \dagger$ \\
\hline Don't know & 21 & 2 & $2.33(0.506,10.767)$ & $4.189(0.819,21.435)$ \\
\hline
\end{tabular}

N.B $*$ significant at $\mathrm{P}-$ Value $<=0.25 \uparrow$ statistically significant at $\mathrm{P}-$ Value $<=0.05$

\section{DISCUSSION}

High level of awareness and willingness to participate and pay a premium are some of the prerequisite factors which could contribute to a successful SHI scheme (14). Surprisingly, more than half $(55.2 \%)$ of the teachers in this study have not ever heard of the proposed health insurance scheme. However, this study revealed that that $71.3 \%$ of the respondents were willing to join the scheme. Of these, $74.4 \%$ were willing to pay. Moreover, $47.1 \%$ of the willing were ready to contribute greater than or equals to $4 \%$ of their monthly salary as a monthly premium. This was lower than the study done in Accra, Ghana, in 2002, and the one done in Nigeria in 2010 where willingness to pay was $6 \%$, but higher than the study done in Kampala District, Uganda, where willingness to pay was $4 \%(11,12,14)$. This difference might be caused by differences in the benefit packages that the schemes cover.

In terms of the method of payment for medical bills, it was found out that $87.7 \%$ of the respondents used out-of-pocket financing to cover their medical bills. This is in line with studies conducted on government employees in African context in $2011(7,17)$. The possible explanation might be employees from the public sector are not assisted in organizing their health care. Consequently, they use the out-of-pocket payment system to cover their health bills.

This study uncovered that problem of paying medical bills predicted the willingness to pay for SHI scheme. This partly agrees with a study done in rural China which indicated that individuals who were in the very worry bracket were more likely to be willing to pay for SHI than those who were not worried about medical expenditure (18).

Furthermore, educational status of the respondent was one of the strong predictors for WTP. Respondents with higher education were more likely to be willing to pay than their lower level counterparts. This is more or less comparable with the findings of Barnighausen T et al (19), Zhang L et al (18) and others $(11,20,21)$.

This might be due to the fact that people with higher education were more confident in adjusting to and trusting a new system that could be attributed to a positive relationship between a 
person's educational level and propensity to acquire skills (24). Besides, they also have better knowledge about the advantage of making regular small insurance payments to avoid the risk of catastrophic medical expenditures at the time of ill health (22).

This study revealed that WTP was predicted by the awareness of respondents about the very basics of health insurance. Individuals who heard about health insurance scheme were 2.5 times more likely to be willing to pay as compared to those who have never heard of health insurance scheme. This finding is consistent with results obtained by Liu and Inke M et al $(22,23)$.

It was found that people who never got married were 2.7 times more likely to be WTP for the SHI scheme as compared to married counterparts. This finding is intuitively sensible since any increase in the household size while holding the income constant reduces the per capita income. However, sex was not found to be significant predictor of WTP for the scheme. To increase the validity of contingent valuation studies the test-re-test method should have been used but due to time and other resource constraints, this was not done in this study. Additionally, the study did not contain insurancespecific attributes like co-payments and deductibles.

In conclusion, more than half of the teachers in government educational institutions have no awareness of the very basics of health insurance. However, three fourth of those WTJ were WTP for the proposed SHI scheme. WTP was found to be predicted by educational status, marital status, history of problem of paying medical bills, awareness on the basics of health insurance, and the perception about who should pay insurance premium. Thus, it is recommended that health policy makers should engage key stakeholders such as teachers in awareness creation and raising activities, and should promote the scheme so that every employee will be conversant in it for successful implementation. Moreover, the commitment of the Federal MOH to implement the scheme should be sustained since findings are encouraging.

\section{ACKNOWLEDGEMENTS}

We thank Jimma University for funding the study. We would like to acknowledge all study participants for their willingness to provide the necessary information.

\section{REFERENCES}

1. International labor organization (ILO). An ILO strategy towards universal access to health care, global campaign on social security and coverage for all. ILO 2007; 34-9.

2. Asgary A, Willis K, Taghvaei A.A, and Rafeian M. Estimating rural households' willingness to pay for health insurance. Eur $J$ Health Econom 2004; 5:209-215.

3. Abel-Smith B. An introduction to health Policy. Planning and financing New York. Longman Group 1994; 78-9.

4. World Health Organization. Paying for health services. Geneva, Switzerland 2007; 123-6.

5. Hsiao W.C and Shaw R.P. Social health insurance for developing nations. Washington: the international bank for reconstruction and development. The World Bank 2007; 31-4.

6. De Allegri M, Sanon M and Sauerborn R. "To enroll or not to enroll?" A qualitative investigation of demand for health insurance in rural West Africa. Soc Sci Med 2006; 62: 1520-1527.

7. McIntyre D, lucy $G$ and Vimbayi $M$. Promoting equitable health care financing in the African context: Current challenges and future prospects. Global Forum for Health Research 2007; 45-8.

8. Damen H. Exploring alternatives for financing health care in Ethiopia: An introductory Review article. Ethiop. J. Health Dev 2001; 15(3):153-163.

9. Federal Ministry of Health Planning and Programming Department. Health Insurance Strategy. Addis Ababa 2008; 13-7.

10. Federal Democratic Republic of Ethiopia Ministry of Health. Health Sector Development Program 2010/11 - 2014/15. Ministry of health Ethiopia 2010; 33-7.

11. Gertler, P. "On the Road to Social Health Insurance". World Development 1998; 26(4): 717-732. 
12. Byabashaija A.A. The knowledge and views of teachers in government educational institutions in Kampala district on the proposed social health insurance scheme in Uganda. UMU Press 2009; 7(1): 1-9.

13. Constella Futures, New Delhi. Health insurance needs awareness and assessment in the Bahraich district, Uttar Pradesh. USAID/India 2008; 35-56.

14. Osungbade KO, Olumide A, Balogun O, Famakinwa EO and Jaiyeoba O. Social Health Insurance in Nigeria: Policy Implications in a Rural Community. Nigerian Medical Practitioner 2010; 57(5-6): 90-95.

15. Karen G, Fleischman F and James R. Willingness to pay surveys for setting prices for reproductive health products and services a user's manual. U.S. Agency for International Development (USAID): Population Council 2004; 5-6.

16. Wedgwood A and Sanson K. willingness to pay surveys: streamlined approach. WEDC, Loughborough United 2003; 57-72.

17. Kayiba T and Rankhumise E M. Employees' perceptions regarding social health insurance: A case of Kinshasa, Democratic Republic of Congo. African Journal of Business Management 2011; 5(28): 11309-11315.

18. Zhang L, Wang H, Wang L and Hsiao W. Social capital and farmer's willingness-to-join a newly established community-based health insurance in rural China. ELSEVIER health policy 2006; 76: 233-242.
19. Barnighausen T, Liu Y, Zhang $X$ and Sauerborn R. Willingness to pay for social health insurance among informal sector workers in Wuhan, China: a contingent valuation study. BMC Health Services Research 2007; 7:114.

20. Dong H, Kouyate B, Cairns J, Mugisha F and Sauerborn R. Willingness-to-pay for community-based insurance in Burkina Faso. Euro Journals 2009; 12: 849-862.

21. Shimeles O, Chali J, Yohannes H and Girma B. Indigenous community insurance (Iddirs) as an alternative health care financing in Jimma city, southwest Ethiopia. Ethiop $J$ Health Sci 2009; 19: 53-60.

22. Liu T. and C. Chen. An Analysis of Private Health Insurance Purchasing Decision with National Health Insurance in Taiwan. Social Science and Medicine 2002; 55:755-774.

23. Mathauer I, Schmidt J and Wenyaa $M$. Extending social health insurance to the informal sector in Kenya. An assessment of factors affecting demand. Int J Health Plann Mgmt 2008; 23: 51-68.

24. Grossman M. On the concept of health capital and the demand for health. Journal of Political Economy. 1972; 80(2):223-255. 